\title{
Dinâmica prazer-sofrimento no trabalho: estudo de caso com funcionários públicos da câmara municipal de Contagem (MG)
}

Procurou-se, neste estudo, analisar o prazer e o sofrimento vivenciados pelos funcionários públicos da Câmara Municipal de Contagem-MG, tendo por base a abordagem de Mendes e Ferreira (2007). O método utilizado foi o estudo de caso, a pesquisa foi descritiva com abordagem qualitativa, servindo-se de um roteiro de entrevista semiestruturado que foi aplicado em dez funcionários públicos, sendo que as entrevistas foram gravadas e, posteriormente, transcritas para a realização da análise de conteúdo. Foram estudadas cinco categorias, das quais emergiram subcategorias. Em relação à organização do trabalho, o ritmo de trabalho é considerado normal e tranquilo, não há cobrança por desempenho ou fiscalização no trabalho e há falta de planejamento para as tarefas. Quanto às condições do trabalho, há falta de segurança, pois a Câmara, em alguns momentos, fica aberta ao público. O ambiente físico é adequado para o trabalho, assim como os instrumentos e os equipamentos o são. No que concerne às relações socioprofissionais, a distribuição das tarefas é feita de modo claro e normal, há cooperação entre os trabalhadores e não há disputas no ambiente. O custo físico foi considerado de pouco esforço, pois a maioria dos profissionais exercem funções de escritório. No que se refere ao custo cognitivo, observou-se que as tarefas são repetitivas e simples, requerendo pouco da cognição do trabalhador. Sobre o custo afetivo, os funcionários disfarçam seus sentimentos e suas opiniões, para o bom convívio com os colegas e com a chefia, e se servem do bom humor que deriva dessa necessidade de dissimularem os sentimentos. As vivências de prazer descritas estão ligadas à organização do ambiente de trabalho, uma vez que os funcionários se sentem como parte integrante do progresso realizado ao longo dos anos; ao reconhecimento pelo bom trabalho que desempenham e à liberdade para se expressarem com seus superiores sobre o trabalho. Já sobre as vivências de sofrimento, os pesquisados consideram a falta de reconhecimento profissional, com pouca gratificação ou melhoria de cargos, decorrendo disso injustiças e discriminações. Em relação às estratégias para lidar com o sofrimento no trabalho, os entrevistados alegaram que se servem da fé, da alegria no trabalho, da ideia de que ali tiram o sustento da família, além de procurarem também o lazer. A respeito dos danos físicos, ressaltaram que desenvolveram L.E.R, dores nos joelhos e bursite. Com relação aos danos psicossociais, consideram que não há conflitos familiares decorrentes do trabalho, nem mesmo há vontade de abandonar tudo, e, se pudessem voltar atrás, reiniciariam a trajetória no mesmo trabalho apesar dos desafios.

Palavras-chave: Funcionários Públicos; Prazer no Trabalho; Sofrimento no Trabalho.

\section{Dynamics pleasure-suffering at work: a case study with civil servants of the municipal council of Contagem (MG)}

\begin{abstract}
The aim of this study was to analyze the pleasure and suffering experienced by public officials of the Municipal Council of MG, based on Mendes and Ferreira (2007). The method used was the case study, the research was descriptive with a qualitative approach, using a semi-structured interview script that was applied to ten public employees, and the interviews were recorded and later transcribed for the analysis Of content. Five categories were studied, from which emerged subcategories. Regarding the organization of work, the pace of work is considered normal and quiet, there is no charge for performance or supervision at work and there is a lack of planning for the tasks. As for the conditions of work, there is a lack of security, because the Chamber, in some moments, is open to the public. The physical environment is suitable for work, just as the instruments and equipment are. As regards socio-professional relations, the distribution of tasks is done in a clear and normal way, there is cooperation between workers and there are no disputes in the environment. The physical cost was considered of little effort, since most professionals perform office functions. With regard to cognitive cost, it was observed that the tasks are repetitive and simple, requiring little of the worker's cognition. On affective cost, the staff disguises their feelings and their opinions, for the good conviviality with the colleagues and the head, and if they use of the good humor, that derives from this necessity to dissimulate the feelings. The experiences of pleasure described are related to the organization of the work environment, since the employees feel like an integral part of the progress made over the years; Recognition for the good work they do and the freedom to express themselves with their superiors about work. Already on the experiences of suffering, the respondents consider the lack of professional recognition, with little gratification or improvement of positions, resulting in injustices and discrimination. In relation to strategies to deal with suffering at work, the interviewees claimed that they use faith, joy at work, the idea that they take the family's livelihood there, and also seek leisure. Regarding the physical damages, they emphasized that they developed L.E.R, knee pain and bursitis. With regard to psychosocial damages, they consider that there are no family conflicts arising from work, nor is there any desire to abandon everything, and if they could turn back, they would resume their work in the same job despite the challenges.
\end{abstract}

Keywords: Public workers; Pleasure in the Work; Suffering at Work.

Topic: Gestão Pública

Reviewed anonymously in the process of blind peer

Rômulo Oliveira Chaves

Faculdade Novos Horizontes, Brasil

http://lattes.cnpq.br/1115400870396902

romulochaves@yahoo.com.br

Fernando Garcia Coutinho

Universidade de São Paulo, Brasil

http://lattes.cnpq.br/4973183681192358

fernando.coutinho@unihorizontes.br

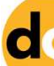

DOI: 10.6008/SPC2179-684X.2016.001.0018
Received: 08/08/2015

Approved: 19/01/2016
Referencing this:

CHAVES, R. O.; COUTINHO, F. G.. Dinâmica prazer-sofrimento no trabalho: estudo de caso com funcionários públicos da câmara municipal de Contagem (MG). Revista Brasileira de Administração Científica, v.7, n.1, p.262-276, 2016. DOI: http://doi.org/10.6008/SPC2179-684X.2016.001.0018 


\section{INTRODUÇÃO}

Este trabalho tem como objetivo, descrever e analisar as vivências de prazer e sofrimento dos funcionários públicos da Câmara Municipal de Contagem-MG, considerando a abordagem de Mendes e Ferreira (2007).

O trabalho sempre fez parte da evolução histórica do homem, porquanto, para sobreviver, ele precisa trabalhar; é um elemento constituinte da essência do indivíduo, pois Ihe propicia o aprendizado e o integra à sociedade (HELLER, 2000); é de suma importância para o indivíduo, pois é no trabalho que ele constrói a sua subjetividade, faz os seus elos sociais, distendendo daí fontes de prazer ou sofrimento, permitindo fazer uma ponte entre o mundo interno e externo do trabalhador (MENDES, 1995; MENDES; MORRONE, 2002).

A Psicodinâmica do Trabalho é uma abordagem científica desenvolvida na França, na década de 1980, pelo médico francês, Christophe Dejours, que pesquisa, há mais de trinta anos, o sofrimento psíquico e as estratégias de enfrentamento usadas pelos trabalhadores para superação e transformação do trabalho em fonte de prazer (DEJOURS, 2004). Trata-se de uma teoria que propicia compreender a subjetividade do trabalho contemporâneo a partir da criação de espaços para discussão, em que os trabalhadores puderam expor sua voz, seus sentimentos e, sobretudo, as contradições que envolvem o trabalho, que é responsável pela maioria das causas geradoras de prazer e sofrimento (DEJOURS, 1992).

Segundo Oliveira (2001), o prazer é vivenciado quando o indivíduo tem liberdade para usar a sua criatividade e deixar sua marca pessoal naquilo que faz, tendo o reconhecimento dos colegas e da chefia pelo papel que desempenha na organização em que trabalha e na qual ele percebe um reflexo na sociedade. Trata-se de uma fonte de prazer, porque o sujeito constrói a sua identidade, considerando o reconhecimento pelo seu empenho ao exercer sua função no trabalho (ENRIQUEZ, 2001).

Há, na Câmara Municipal de Contagem (CMC), uma dicotomia no modo de contratação do funcionário público - o estatutário que é o funcionário que ocupa o cargo por ter sido aprovado em concurso público e que tem um vínculo estatutário, regido pelo Estatuto dos Funcionários Públicos, possuindo estabilidade no emprego - e do celetista, que é nomeado para cargo comissionado pelos vereadores da Câmara e tem vínculo segundo a (CLT) Consolidação das Leis do Trabalho (DI PIETRO, 2002). O celetista não possui estabilidade e sua relação com a Câmara é mais para manter o mandato e reeleger o vereador do que para exercer as funções que Ihes são designadas pela contratação, sobrecarregando os funcionários de carreira e criando discórdia e problemas pessoais no ambiente de trabalho. Isso desrespeita o princípio de eficiência requerido ao agente público, conforme de Di Pietro (2002), para alcançar os melhores resultados, e perturba o modo racional de se organizar, estruturar e disciplinar a administração pública, com o intento de atingir os resultados necessários na prestação do serviço público. 


\section{REVISÃO TEÓRICA}

\section{Psicodinâmica do Trabalho}

São objetos de estudo da psicodinâmica o trabalho, as interações dinâmicas entre a organização do trabalho e os métodos de subjetivação do indivíduo, método esse que confere sentido construído em si mesmo, fundamentado no relacionamento do funcionário e sua vida no trabalho, e evidenciado na sua forma de presumir, perceber e realizar (MENDES, 2007).

A psicodinâmica do trabalho tem uma abordagem que vai além da teoria e da pesquisa, sendo, também, um modo de ação na organização do trabalho. Ela faculta um entendimento sobre a subjetividade do indivíduo no trabalho, criando-se uma clínica, onde se pode estabelecer espaços em que o sujeito pode se expressar oralmente, expondo seus sentimentos e suas contradições observadas no contexto do trabalho, que, invariavelmente, são fontes de prazer e sofrimento (DEJOURS, 1992).

Segundo Dejours (2004), por meio da psicodinâmica do trabalho faz-se a pesquisa da vida psíquica no trabalho, tendo como foco principal o sofrimento psíquico do trabalhador e as estratégias de enfrentamento utilizadas pelos trabalhadores para a superação e transformação do trabalho em fonte de prazer.

Neste mesmo entendimento, Mendes (2003) afirma que é também objeto da Psicodinâmica do trabalho o estudo das relações dinâmicas entre organização do trabalho e processos de subjetivação, que se manifestam nas vivências de prazer-sofrimento, nas estratégias de ação para mediar contradições na organização do trabalho, nas patologias sociais, na saúde e no adoecimento.

Para a psicodinâmica do trabalho, o prazer pode ser vivenciado até mesmo em condições precárias, quando a organização do trabalho permitir que o trabalhador desenvolva ações de mobilização da inteligência prática, do espaço público da fala e da cooperação (MENDES, 2007).

\section{Prazer do Trabalho}

O prazer é um sentimento que advém da realização do potencial do ser humano, sendo que essa realização desperta no indivíduo a consciência de que ele pode sobrepor-se às condições adversas do meio ao qual está inserido, despertando no indivíduo o sentimento de autoconfiança, de ser necessário, competente, importante, enfim, ser uma pessoa que consegue lidar com as circunstâncias à medida que elas surgem, servir-se de sua própria capacidade e ser livre para expressar seus sentimentos (SCHUTZ,1974).

O prazer é vivenciado quando a execução do trabalho permite a valorização e o reconhecimento do trabalhador, quando ele sente que sua participação é importante tanto na organização quanto na sociedade, quando pode expressar-se e deixar no que faz a marca de sua personalidade, aliando a isso admiração e respeito pelo modo como executa suas responsabilidades. Assim, tanto a criatividade como a liberdade de expressão pessoal, o orgulho pelo que faz e o reconhecimento do esforço que empreende pelos dirigentes da organização e colegas são fontes de prazer (MENDES; ABRAHÃO, 1996). 
A busca pela segurança manifesta-se pela necessidade de estabilidade e proteção. $O$ homem privado da satisfação desta necessidade apresenta um comportamento de inibição da criatividade ao assumir riscos. A busca pela satisfação é constante. As necessidades de participar de um grupo, de ser aceito por ele, de fazer amizades têm relevante papel na vida do homem no trabalho, visto que o indivíduo apresenta intensa necessidade de associar-se e de relacionar-se, procurando colaborar com seus pares no ambiente de trabalho (SOTO, 2005).

No contexto da relação do sujeito com o trabalho, Carneiro (2000) afirma que o que permite uma relação complementar do homem com o seu trabalho é o fato de ele poder ter um significado individual e social que ultrapasse a produtividade em si. É preciso que o trabalho atenda às exigências subjetivas da pessoa e responda aos princípios éticos do grupo.

\section{Sofrimento no Trabalho}

Para Ferreira e Mendes (2001), o sofrimento pode ser definido pelo fator do desgaste, que é a sensação de cansaço, desânimo e descontentamento com o trabalho. Desse modo, percebe-se uma discrepância entre a tarefa solicitada e a atividade real, enquanto produtora de um custo psíquico para o trabalhador, trazendo consequências para a organização e interferindo negativamente na maneira como a tarefa é desempenhada e nas relações socioprofissionais. Isso impõe ao indivíduo um estado de esforço demasiado e intenso para desempenhar as funções que, muitas vezes, são incompatíveis com suas habilidades e condições psicológicas, produzindo assim sofrimento.

De acordo com Brant e Minayo-Gomez (2004), é importante reconhecer que o sofrimento não se manifesta de uma única forma em todos os indivíduos de uma mesma família, cultura ou de um mesmo período histórico. O que é sofrimento para um, não é, necessariamente, para outro, mesmo quando submetidos às mesmas condições ambientais adversas. Ou ainda, aquilo que é sofrimento para alguém, pode ser prazer para outro e vice-versa. Um acontecimento, como algo capaz de provocar um espanto, em um determinado momento pode significar sofrimento; em outro, pode ser vivenciado como satisfação. Resta, ainda, lembrar que no sofrimento é possível encontrar uma mescla de prazer e dor simultaneamente.

Oliveira e Vieira (2009) ressaltam que é imprescindível para a organização saber os motivos pelos quais os trabalhadores sofrem, e, muitas vezes, é a própria organização a causadora de tais distúrbios, seja pela sobrecarga do serviço, assédio, instabilidade ou insegurança.

É importante considerar o quanto o sofrimento e a angústia estão entrelaçados no mundo do trabalho e podem acarretar o adoecimento psíquico. Esse, por sua vez, gera discriminação e incentiva o receituário indiscriminado de ansiolíticos e antidepressivos, tirando o foco do adoecimento causado pelo ambiente de trabalho e voltando-o para o trabalhador (BARROS; ANDRADE; GUIMARÃES, 2008).

Em virtude dos objetivos capitalistas, que é o foco das organizações, elas banalizam a questão das expectativas do sujeito, o que determina o distanciamento do trabalhador da organização, iniciando-se, assim, o ciclo do sofrimento vivido pelo indivíduo como elucida Mendes (2007): “[...] o sofrimento surge quando não é mais possível a negociação entre o sujeito e a realidade imposta pela organização do trabalho". 
Ferreira e Mendes (2001) ressaltam que o modo como o trabalho é realizado permite definir se a atividade é significativa ou não para o trabalhador, influenciando o sentido que ela assume para cada indivíduo, sendo que é da construção desde sentido específico que emergem vivências de prazer e sofrimento.

Dejours (1994) reflexiona que existe um limite entre o sofrimento e a negociação em determinada organização. O sofrimento normalmente está associado a doença, ou seja, os sintomas físicos refletem os conturbados problemas emocionais.

Para Mendes (1999), o sofrimento no trabalho é caracterizado quando o sujeito, no seu cotidiano passa por experiências dolorosas, tais como, insegurança, medo, angústias advindas das imposições de suas tarefas. Há sofrimento, então, quando o trabalhador não obtém gratificação ou reconhecimento, ou quando não há correspondência entre as suas necessidades sociais e cognitivas e as exigências do trabalho.

\section{Estratégias de Enfrentamento face ao Sofrimento}

Dejours (1987) preceitua que estratégias defensivas são mecanismos desenvolvidos pela inteligência para lidar com o sofrimento e para a construção da identidade no trabalho. Além disso, o autor defende que a psicodinâmica do trabalho foi a abordagem que levou à compreensão de que o trabalhador não é o único responsável pelas consequências que influem negativamente em sua saúde.

Levando-se em conta as diversas dificuldades com as quais o trabalhador é defrontado no seu ambiente de trabalho e na organização, o indivíduo acaba por desenvolver estratégias para mediar o sofrimento, de modo sutil, engenhoso, diversificado e criativo, contando, com isso, sobrepor as condições adversas no trabalho, esforçando-se para minimizar o sofrimento e criar um obstáculo ao adoecimento (MENDES, 2007).

Desse modo, para o indivíduo cumprir as tarefas exigidas pela organização e não adoecer, ele servese de estratégias de enfrentamento contra o sofrimento, como o individualismo, negação do perigo, conformismo, agressividade, passividade, dentre outras. O uso dessas estratégias de defesa visa manter o equilíbrio psíquico, porquanto permitem o enfrentamento das situações que causam o sofrimento (DEJOURS, 1987).

Estas estratégias têm suas especificidades, em vista das diferentes categorias profissionais que as adotam, podendo ser individuais e coletivas. Dejours, Abdoucheli e Jayet (1994) ensinam que as estratégias individuais não têm a presença física do objeto, ou seja, já estão interiorizados; as estratégias coletivas necessitam da presença de condições externas e se mantêm em consenso de um grupo de trabalhadores. A racionalização, a sublimação, a ressonância simbólica, a inteligência astuciosa e o uso da palavra são mecanismos desenvolvidos para o enfrentamento de sofrimento (BARROS, 2012).

Segundo Macêdo e Fleury (2012), as estratégias de defesa tencionam adequar o indivíduo às pressões de trabalho com a finalidade de impedir o sofrimento, diferentemente dos mecanismos de defesa e do ego, por serem interiorizados e persistirem a partir da presença de uma circunstância externa. 


\section{METODOLOGIA}

Para a realização do estudo proposto, optou-se pelo tipo de pesquisa descritiva, abordagem qualitativa, servindo-se do método de estudo de caso, com o intuito de analisar e descrever o prazer e o sofrimento dos funcionários públicos perante a realidade e o cotidiano na Câmara Municipal de ContagemMG.

Triviños (1987) ressalta que um dos importantes aspectos da pesquisa descritiva é "conhecer a comunidade, seus traços característicos, suas gentes, seus problemas [...]", buscando entender a complexidade do contexto social em que labutam os pesquisados. $O$ autor esclarece ainda que nas pesquisas descritivas há mais exigência de investigação por parte do investigador, "para que a pesquisa tenha certo grau de validade científica, uma precisa delimitação de técnicas, métodos, modelos e teorias que orientarão a coleta e interpretação dos dados" (TRIVIÑOS, 1987).

Quanto à abordagem, optou-se pela qualitativa, pois caracteriza o ambiente natural como fonte direta de dados e define o pesquisador como o instrumento principal para analisar os dados colhidos, servindo-se do enfoque indutivo. Além disso, o pesquisador ainda adapta as investigações dos grupos e os segmentos determinados, focando as histórias sociais segundo a ótica dos sujeitos e das relações para averiguar com agudez os discursos e documentos (GODOY, 1995; TEIXEIRA, 2003; MINAYO, 2007).

A abordagem qualitativa apresenta-se como a mais adequada para compreender e, sobretudo, analisar as causas do prazer e sofrimento que acometem os funcionários públicos da Câmara Municipal de Contagem-MG, tendo em vista as relações do cotidiano e os sentimentos distendidos desta vivência, Segundo Minayo (1996), a abordagem qualitativa:

É aquele capaz de incorporar a questão do significado e da intencionalidade como inerentes aos atos, às relações e às estruturas sociais, sendo essas últimas tomadas tanto no seu advento quanto na sua transformação, como construções humanas significativas (MINAYO, 1996).

O método utilizado é o Estudo de Caso, pois, por meio dele, estuda-se uma família, um grupo e mesmo uma comunidade específica que represente um universo, tendo por finalidade averiguar aspectos determinados de sua vida. Este método é muito utilizado em pesquisas qualitativas e nas ciências humanas, principalmente porque permite analisar de modo profundo e abrangente os aspectos marcantes e característicos de um grupo específico (BARROS; LEHFELD, 2000; CERVO, BERVIAN; DA SILVA, 2007).

Segundo Yin (2010), o estudo de caso "investiga um fenômeno contemporâneo dentro de seu contexto da vida real [...] quando os limites entre o fenômeno e o contexto não estão claramente definidos", permitindo, ao pesquisador, entender o contexto social de modo profundo, a partir da averiguação minuciosa das informações colhidas junto aos indivíduos pesquisados.

Alves-Mazzotti e Gewandsznajder (1999) esclarecem que é imprescindível a compreensão sobre a unidade de análise, sendo que ela pode ser uma organização, um grupo, diferentes subgrupos em uma comunidade específica ou, também, certos indivíduos. Para este caso a unidade de análise foi a Câmara 
Municipal de Contagem (MG). De acordo com Vergara (2007), os sujeitos da pesquisa são as pessoas que fornecerão os dados que o pesquisador precisa para a pesquisa.

A pesquisa foi realizada com dez funcionários públicos da Câmara Municipal de Contagem (MG), sendo que os pesquisados foram escolhidos pelos critérios de disponibilidade e acessibilidade como preceitua Vergara (2007). O pesquisador teve acesso à organização pesquisada, e, com permissão dos superiores e aquiescência dos funcionários públicos, foram realizadas as entrevistas no ambiente de trabalho, cuja duração média foi de 45 minutos.

A entrevista semiestruturada foi a opção escolhida para a coleta de dados, servindo-se das dimensões do Inventário sobre o Trabalho e Risco de Adoecimento (ITRA), de Mendes e Ferreira (2007), que foi adaptado para a abordagem da pesquisa. Para Cervo, Bervian e Da Silva (2007), a entrevista semiestruturada "não é uma simples conversa. É uma conversa orientada para um objetivo definido: recolher, por meio do interrogatório do informante, dados para a pesquisa". Assim como é um dos "instrumentos básicos para a coleta de dados, dentro da perspectiva de pesquisa". Esta é, aliás, "uma das principais técnicas de trabalho utilizada em quase todos os tipos de pesquisa realizadas nas ciências sociais" (LUDKE; ANDRE, 1986). O roteiro de perguntas utilizada nesta pesquisa foi adaptado de (GUABIROBA, 2012).

Para Gil (1999), a entrevista semiestruturada é a técnica em que o investigador se coloca defronte ao investigado e lhe faz perguntas, com o intuito de obter os dados que interessam à investigação. A entrevista é, então, uma forma de interação social, ou seja, uma maneira de diálogo assimétrico, em que uma das partes coleta dados, e a outra se coloca como fonte de informação, por isso, os autores defendem que é fundamental a interação na entrevista, pois enriquece e aprofunda os objetivos da pesquisa.

Para a análise dos dados colhidos nas entrevistas, optou-se pela técnica de análise de conteúdo fundamentada nos preceitos de Bardin (1977). A análise de conteúdo possibilita aos investigadores sistematizar a compreensão de maneira a alcançar maior profundidade dos relatos, conseguindo esclarecer e identificar informações retidas nas entrelinhas das entrevistas, sobretudo por meio de interpretações e codificação de mensagens, baseando-se nas deduções dos dados obtidos (BARDIN, 1977).

Quadro 1: Perfil dos funcionários públicos entrevistados.

\begin{tabular}{|c|c|c|c|c|c|c|c|}
\hline Entrevistado & Sexo & $\begin{array}{c}\text { Estado } \\
\text { Civil }\end{array}$ & Residência & Idade & Escolaridade & $\begin{array}{c}\text { Tempo de Serviço na } \\
\text { Câmara Municipal }\end{array}$ & $\begin{array}{c}\text { Regime de } \\
\text { Trabalho }\end{array}$ \\
\hline E1 & $\mathrm{F}$ & Solteira & Contagem & 55 & Ensino Superior & 17 anos & CLT \\
\hline E2 & $\mathrm{M}$ & Casado & Contagem & 39 & Ensino Superior & 3 anos & Estatutário \\
\hline E3 & $\mathrm{F}$ & Casada & Contagem & 54 & Ensino Superior & 23 anos & CLT \\
\hline E4 & $\mathrm{F}$ & Casada & Contagem & 56 & $\begin{array}{c}\text { Ensino Superior } \\
\text { Incompleto }\end{array}$ & 28 anos & Estatutário \\
\hline E5 & $\mathrm{F}$ & Solteira & Contagem & 52 & $\begin{array}{c}\text { Ensino Superior } \\
\text { Incompleto }\end{array}$ & 27 anos & Estatutário \\
\hline E6 & $\mathrm{F}$ & Casada & Contagem & 43 & Ensino Médio & 17 anos & Estatutário \\
\hline E7 & $\mathrm{F}$ & Divorciada & Contagem & 56 & Ensino Médio & CLT \\
\hline E8 & $\mathrm{M}$ & Casado & Contagem & 59 & Ensino Superior & 20 anos & Estatutário \\
\hline E9 & $\mathrm{M}$ & Divorciado & Contagem & 53 & Ensino Médio & 3 anos & Estatutário \\
\hline E10 & $\mathrm{F}$ & Divorciada & Contagem & 62 & Ensino Médio & & \\
\hline
\end{tabular}




\section{RESULTADOS}

A seguir, apresentam-se as categorias e subcategorias relacionadas ao núcleo de sentido produzido, considerando-se os objetivos da pesquisa, que foram definidos a partir das quatro dimensões do ITRA.

Quadro 1: Análise do Núcleo de Sentidos (ANS).

\begin{tabular}{|c|c|c|}
\hline CATEGORIA & SUB-CATEGORIA & NÚCLEO DE SENTIDO \\
\hline \multirow{3}{*}{ Contexto do Trabalho } & Organização do trabalho & Ritmo não intenso, tranquilo. \\
\hline & Ambiente físico & Equipamentos e ambiente físico adequados, pouca segurança. \\
\hline & $\begin{array}{c}\text { Relações } \\
\text { socioprofissionais }\end{array}$ & $\begin{array}{l}\text { Distribuição normal, tranquila e clara das tarefas, cooperação entre } \\
\text { os pares. }\end{array}$ \\
\hline \multirow[t]{2}{*}{ Custos do trabalho } & Físico e cognitivo & $\begin{array}{l}\text { Há esforço físico (digitação), e pouca exigências intelectuais (tarefas } \\
\text { rotineiras). }\end{array}$ \\
\hline & Afetivo & Necessidade de disfarçar os sentimentos, bom humor. \\
\hline \multirow{2}{*}{ Sentidos do trabalho } & Vivências de prazer & Gosta do que faz, participar do progresso do ambiente de trabalho. \\
\hline & Vivências de Sofrimento & Falta de reconhecimento pelos superiores. \\
\hline $\begin{array}{l}\text { Estratégias de } \\
\text { enfrentamento }\end{array}$ & & Distração, relevar as dificuldades. \\
\hline
\end{tabular}

Com relação ao ritmo do trabalho, os funcionários públicos ressaltaram que é tranquilo, pois há tempo hábil para realização das tarefas incumbidas a cada trabalhador como se pode averiguar nos depoimentos abaixo:

Olha meu ritmo de trabalho e tranquilo não tem muito esforço e gosto muito do que faço, apesar de ser um trabalho não muito reconhecido, né, mas eu não tenho nada a reclamar (E10)

Meu trabalho é bom aqui, o ritmo não é intenso, a gente trabalha aqui com folga, tem dia que está mais apertado, tem dia que não, igual ao final do mês que é fechamento, pagamento é mais apertado, mais durante ou no meio do mês já fica mais tranquilo (E3)

Os funcionários públicos da Câmara Municipal de Contagem-MG ressaltaram, nos depoimentos, que o ritmo de trabalho é tranquilo, o que encontra respaldo nos preceitos de Mendes (2007), quando postula que para vivenciar prazer no trabalho e na tarefa executada, é imprescindível que se adapte a condição e a capacidade do trabalhador a um ritmo de trabalho e a uma jornada que o deixe confortável, não influindo, assim, negativamente em seu estado psicológico.

Com referência à segurança física, os pesquisados relataram que se sentem inseguros, pois, mesmo com a instalação catracas na portaria, há dias em que elas são retiradas e, como a Câmara Municipal é a casa do povo, qualquer pessoa pode entrar e, em algumas circunstâncias, constranger os funcionários como se pode atestar nos depoimentos abaixo:

Existe os vigias da Câmara e existe também os guardas municipal que apoia a segurança no setor. No meu ponto de vista, não é seguro, eu sempre defendi que deveria ter uma vigilância armada. (E9)

Regular, eu fico preocupada, quando eu trabalhava lá em cima, tinha uma sala mais afastada e você sabe como político é famoso, né, então chegava gente assim meio nervoso, agitado, procurando vereador. (E7)

Os relatos dos funcionários públicos encontram ressonância nos postulados de Brant e MinayoGomez (2004), que esclarecem que vários fatores podem levar o indivíduo ao sofrimento, desde um leve susto até o risco iminente da sua integridade física ou mesmo angústia. Mendes (1999) elucida que o 
sofrimento provém de experiências dolorosas, como insegurança, medo, angústias, provenientes do ambiente de trabalho ou as que eles são a causa.

Segundo os relatos dos entrevistados, o ambiente de trabalho é adequado, tem boas condições para a realização das tarefas e dispõe conforto para os trabalhadores conforme os depoimentos:

Meu ambiente físico é muito tranquilo, nós temos uma sala reservada, não tem ninguém perturbando, não tem perturbação externa de gente chegando toda hora. (E1)

Bom, o ambiente é tranquilo, mas como a gente trabalha com números e pagamentos e tal, então tem que ser um ambiente igual a gente trabalha, tranquilo e sem muita cobrança (E3)

A este respeito, encontra-se respaldo na literatura específica, sobretudo em Oliveira (2001), quando afirma que um ambiente de trabalho adequado e que proponha tranquilidade para o indivíduo desenvolver suas tarefas é imprescindível, considerando que o trabalhador passa grande parte de sua vida naquele local, e a boa harmonia intervém decisivamente na sua saúde mental e no seu estilo de vida.

Sobre a distribuição das tarefas, os entrevistados relataram que ela ocorre de forma normal e clara entre os companheiros de trabalho, pois têm boa convivência e todos conhecem o serviço um do outro, sem que ocorram conflitos por este motivo. Neste quesito, dois pesquisados disseram que o setor em que trabalham é desorganizado e precisaria de melhorias:

Bom, a distribuição de tarefas é que cada um sabe o serviço do outro, nós dois aqui sabemos, eu sei fazer o dele, e ele o meu, então cada um faz e a gente determina o que cada um faz. (E3).

No meu caso aqui na contabilidade, já te falei, as tarefas são de acordo com a legislação, é fazer contabilidade, controlar saldos, essas coisas, e a distribuição é tranquila, eu sou auxiliar técnico, e tá tranquilo a distribuição aqui, não tem problema com isso não (E2).

Os dados confirmam os estudos de Tamayo (2004), ao elucidar que o indivíduo sente prazer quando o ambiente em que trabalha é adequado, quando há estima, reconhecimento e cooperação entre os pares e quando a tarefa designada a ele é coerente com suas habilidades e condições.

Em relação às subcategorias integração e cooperação e à disputa entre os trabalhadores, os pesquisados relataram que há cooperação entre os pares e que não há disputas, pois cada qual tem sua função definida e seu cargo estabelecido e, independentemente do que se faça, o resultado no final do mês não será alterado como se pode atestar nos depoimentos abaixo:

Aqui não dá isso, eu acho que existe competitividade em empresa privada, onde a pessoa precisa passar por cima de outra, só para conseguir uma ascensão profissional. (E1).

Aqui não tem disputa, porque é muito pequeno, somos dois profissionais aqui dentro, acho que isso acontece mais em empresa privada, aqui você já entra em um cargo definido, e, no caso, você vai concursado. (E2).

Os relatos dos entrevistados encontram respaldo em Mendes e Silva (2006), ao afirmarem que a cooperação é um benefício coletivo, enquanto a competição demasiada impede o trabalho diário, lado a lado, pois encrusta sentimentos de simpatia e envolvimento dos funcionários, acarretando danos à instituição, ao trabalho e aos indivíduos. Dejours (2007) compreende que o trabalho ainda é o mediador da realização pessoal e é nele que se pode estabelecer a saúde psíquica e constituir a sua identidade.

Em relação ao custo físico, os entrevistados relataram que não se exige muito deles, pois a maioria exerce tarefas relacionadas a escritório e permanece, a maior parte do tempo, sentado. Mesmo os 
entrevistados que trabalham em setores que exigem algum esforço relataram que o esforço não é tão grande de modo a causar-Ihes algum inconveniente. Apenas dois entrevistados consideraram que mesmo o trabalho de escritório lhes causa cansaço e são passíveis de terem L.E.R como podemos observar nos depoimentos abaixo:

Esforço físico e bater carimbo e digitar, repetição e cansaço (E6).

Esforços físicos eu tenho assim, às vezes quando é muito demorado, eu fico muito cansada, porque só tem uma taquígrafa no departamento e, às vezes, eu escrevo umas 100 e pode causar L.E.R. (E7).

Chanlat (1996) elucida que as organizações públicas estão cada vez mais aderindo ao modo de gestão das empresas privadas, cobrando esforço intensivo tanto físico como mental dos funcionários, o que, ao longo do tempo, acarreta insônia, problemas cardiovasculares e úlceras. Oliveira e Vieira (2009) afirmam que uma das causas do sofrimento no trabalho advém da sobrecarga por excesso de esforços que a organização exige dos funcionários.

Em relação à subcategoria desafios intelectuais impostos pelo trabalho, os funcionários públicos relataram que isso não ocorre, pois, as tarefas são muito simples, rotineiras e pré-estabelecidas. Apenas dois entrevistados disseram que houve mudanças recentes em seus setores e, por isso, foi necessário estudar, e atualizar-se a respeito como se pode deduzir dos depoimentos:

Menino, eu tô emburrecendo aqui, não tenho desafio intelectual aqui, se você não se virar para se manter atualizado, você emburrece, por que não exige que você se mantenha atualizado com relação ao mundo financeiro, não te exige nada, não te exige... nada (E1).

Eu não vejo desafio intelectual não, é muito fácil para ter um desafio intelectual, de vez em quando eu até tenho problemas aqui por exemplo na mesa ou de alguma coisa, mais aí vem um técnico aqui e explica o problema que está acontecendo, é fácil de ser resolvido (E8).

Para Ferreira e Mendes (2001), o sofrimento pode ser vivenciado quando o indivíduo tem a sensação de cansaço, desânimo e descontentamento em relação a um trabalho que se configura repetitivo, maçante, que impõe muito esforço e inibe a criatividade do trabalhador, interferindo, assim, negativamente em seu psiquismo e propiciando o adoecimento.

A respeito do custo afetivo, emergiu a subcategoria que se refere à necessidade de disfarçar as suas emoções para ter um melhor convívio no trabalho, porque a expressão de suas emoções e ideias pode causar problemas, reprimendas e punição pelos superiores como se pode ver nos depoimentos:

Não, aqui você precisa se calar, você precisa omitir suas opiniões e impressões pessoais porque se você falar, não é muito bem visto, então é bem por aí, porque quando você descontrola você é punido por isso (E6).

Lógico, que a gente precisa, a gente está no meio político, se vê que as pessoas não são tão sinceras umas com as outras, porque elas precisam. (E1).

A este respeito, Alencar (1989) salienta que o fato de os trabalhadores se esforçarem para disfarçar seus sentimentos na organização é um dos grandes causadores de sofrimento para o indivíduo, que está inserido em uma cultura em que as pessoas, para serem bem aceitas no meio social, devem controlar suas emoções e manterem-se indiferentes diante de qualquer situação que possa gerar conflitos. Porém, essa circunstância impede o desenvolvimento da criatividade, tolhendo as faculdades do indivíduo e levando-o, assim, a vivenciar o sofrimento. 
Outra subcategoria apresentada foi o humor no trabalho, em que os pesquisados relataram que procuram ter bom humor naturalmente, pois o tempo de convívio e a experiência profissional demonstra que é o melhor comportamento a ser adotado perante o grupo e a chefia:

Ah! Meu humor é muito bom, eu falo para as pessoas às vezes que a gente tá errado, que eu não dou razão para sair de mau humor, e têm pessoas que são ranzinzas de natureza, eu não, tô sempre alegre. (E9).

Sempre bem-humorada, não sou mal-humorada, a gente normalmente não estressa aqui, só quando a cobrança é toda hora, né, é tranquilo aqui. (E3)

Consultando a bibliografia, encontra-se respaldo dos relatos dos funcionários públicos em Dejours, Abdoucheli e Jayet (1994), quando asseveram que o sofrimento produzido pelo trabalho pode ser vivenciado de dois modos: pela elaboração de estratégias de defesa, que possibilitará a sua minimização, ou por meio da ressignificação ou mobilização, que certamente é o caminho indicado para que o indivíduo adquira estabilidade sociopsíquica para transformar o sofrimento em prazer (CARRASQUEIRA; BARBARINI, 2010).

Os pesquisados relataram que sentem prazer ao ver o setor em que trabalharam durante anos organizados e com ótimas condições de trabalho pelo que fizeram, sentem prazer pela responsabilidade que têm com o trabalho e por gostarem do que fazem como se pode perceber pelas falas:

Eu acho que eu consegui organizar, vou conseguir sair daqui com a cabeça erguida e com minha consciência tranquila, e eu coloquei isso aqui organizado. Hoje se você perguntar, me dá a resolução número tal, eu vou ali e pego para você. Antes era tudo lá fora, para mim colocar isso assim, eu fiquei trabalhando 15 dias, pegando 7 horas da manhã, e não tinha hora para largar, tinha dia que dava 10 horas da noite e eu estava aqui para chegar como está agora. Então, estou feliz porque contribui beleza, pode não estar 100\%, mas que está legal está. (E5)

Eu acho que sou motivada porque eu gosto daquilo que eu faço, se você fazer uma coisa que gosta, aí você é motivada, independente do salário, né? Por que no meu caso, eu sou comissionada, eu vou te falar, sou motivada de trabalhar aqui na Câmara, porque eu gosto do que faço entendeu. (E7)

A este respeito Mendes e Abrahão (1996) elucidam que o prazer é vivenciado quando a execução e o que envolve o trabalho permitem a valorização e o reconhecimento do trabalhador. $\mathrm{O}$ trabalhador sente que sua participação é importante tanto na organização quanto na sociedade quando pode expressar-se e deixar a marca de sua personalidade no que faz, aliando a isso a admiração e respeito pelo modo como executa suas responsabilidades. Assim, a criatividade e a liberdade de expressão pessoal, o orgulho pelo que faz e o reconhecimento do esforço que empreende pelos dirigentes da organização e colegas são fontes de prazer.

Em relação às vivências de sofrimento, apresentou-se a subcategoria falta de reconhecimento pelo esforço profissional que os funcionários públicos relatam ser bem raro na Câmara Municipal, causando danos emocionais como se pode observar nos depoimentos abaixo:

É realmente, tem disso aqui, você fica tiririca da vida, para não dizer outras coisinhas. Quer dizer o seguinte, que existe não é a valorização, mas é o seguinte, sempre tem alguém, que independente do que ela faça ou não, ela vai ter algum benefício maior do que o seu. (E1).

Falta de reconhecimento, desvalorização humana, percebo isso, na verdade o servidor público é uma folha de ponto, padecer ou morrer, é substituído por outro e nem lembranças eu acho que fica, todos acabam agindo assim com o passar do tempo também (E6). 
Neste ponto, segundo os relatos, encontra-se respaldo em Mendes (1999), quando diz que o sofrimento no trabalho é caracterizado quando o sujeito, no seu cotidiano, passa por experiências dolorosas, tais como, insegurança, medo, angústias advindas das imposições de suas tarefas, quando não se obtém gratificação ou reconhecimento ou quando não há correspondência entre suas necessidades sociais, cognitivas e as exigências do trabalho. Segundo Amorim e Campos (2002), o reconhecimento dos superiores pelo trabalho que o indivíduo realiza seja por meio de um aperto de mão, premiações salariais ou folgas, desperta prazer e levam o trabalhador a ter felicidade e motivação no trabalho, influenciando a produtividade de cada um e a da organização em geral.

Variadas estratégias para lidar com o sofrimento foram elencadas pelos pesquisados, como abstrairse do trabalho, relevar as dificuldades dos colegas, ter alegria e lazer como se pode averiguar nos depoimentos:

Ninguém desenvolve estratégia para sobrecarga emocional, agora tem que ver se, saindo lá fora, tomando uma cerveja, ou conversando com os amigos, porque do contrário, aqui dentro você não vai ficar dando piti, dando chilique, no mais, quando você vem com pressão de casa, com alguma pressão, com algum problema (E1).

Ah! Eu convivo, pensando que isso aqui vai passar, que existe outras coisas fora daqui, que tenho família para me divertir, que tem outros lugares, aquilo é uma fase da minha vida (E6).

Levando se em conta as diversas dificuldades com as quais o trabalhador é defrontado no seu ambiente de trabalho e na organização, o indivíduo acaba por desenvolver estratégias para mediar o sofrimento, de modo sutil, engenhoso, diversificado e criativo, contando sobrepor as condições adversas no trabalho e esforçando-se para minimizar o sofrimento e criar um obstáculo ao adoecimento (MENDES, 2007).

\section{CONSIDERAÇÕES FINAIS}

Considerando os resultados obtidos pela pesquisa pode-se averiguar que em relação a organização do trabalho, ambiente de trabalho é tranquilo, há tempo hábil para a realização das tarefas, não há cobrança constante dos superiores, sendo que cada um dos funcionários sabe as obrigações inerentes ao cargo e as exerce segundo a demanda do serviço. Todavia, deve-se ressaltar, de acordo com o que se pôde observar, que, muitas vezes, ocorre a falta de cobrança por parte dos superiores, pois eles estão ligados à política e se preocupam mais em reforçar a imagem do candidato que administrar as funções da Câmara. Tal situação reflete na falta de planejamento.

Em relação às condições do trabalho, detectou-se que há insegurança física por parte dos funcionários públicos, pois, ainda que tenha sido recentemente instalada uma catraca que impõe a identificação de todos que entram na Câmara, no dia de funcionamento do plenário com os vereadores, ela é retirada e qualquer pessoa pode entrar no recinto, deixando a vigilância frágil. Durante a campanha, os vereadores assumem muitos compromissos com várias pessoas, e, quando no exercício do mandato não as contemplam, elas entram na Câmara exaltadas, colocando em risco a integridade física dos trabalhadores. $O$ ambiente físico, embora bastante compacto, é suficiente para a realização das atividades incumbidas a cada 
funcionário, e os instrumentos e equipamentos de trabalho são bons e repostos prontamente desde que se necessite deles.

No que se refere às relações socioprofissionais, observou-se que a distribuição das tarefas é feita de maneira normal entre os funcionários e elas estão claramente estabelecidas, pois os cargos que os funcionários públicos irão ocupar já designam as funções no contrato ou no edital. Em alguns casos, essa distribuição é difusa e desordenada, devido ao desleixo da chefia do setor, todavia, a boa cooperação entre os funcionários sobrepõe tais dificuldades, ao verificar que não há disputa nem animosidades.

No que tange aos custos do trabalho, percebeu-se, em referência ao esforço físico, que ele é bem moderado para a maioria dos funcionários, pois suas funções, encerram-se, a mais das vezes, em funções de escritório, que requerem pouca movimentação. O perigo, no entanto, insinua-se para o futuro, devido ao sedentarismo e aos problemas nas articulações que são bem comuns nestes profissionais.

Considerando os custos cognitivos, notou-se que os pesquisados estão alienados, realizando tarefas que não se alteraram ao longo dos anos e, por isso, não têm necessidade alguma de se atualizarem, estudarem ou de mudarem os métodos já estabelecidos. O trabalho não lhes oferece desafio ou propõe mudança alguma, sendo enfadonho na maioria das vezes. Apenas no setor financeiro, devido à mudança das políticas públicas que modificaram os métodos de trabalho, ocorreram mudanças salutares para os trabalhadores, que tiveram a oportunidade de dinamizar o serviço com novas propostas.

No que diz respeito ao custo afetivo, percebeu-se que os funcionários públicos desenvolvem estratégias de defesa, opiniões e controlam suas reações, pois convivem num ambiente politizado, em que um passo maldado pode ser punido. Desse modo, dissimulam seus sentimentos e suas ideias para um bom convívio, como pode ser notado pelo bom humor geral que reina no ambiente de trabalho deles. Para que não venham sofrer qualquer tipo de admoestação, os funcionários públicos optaram por uma conduta de subordinação para manterem suas posições e, em alguns casos, seus benefícios.

Em referência a vivências de prazer e sofrimento, especificamente sobre o prazer, notou-se que os funcionários públicos sentem prazer na trajetória de uma vida dedicada à Câmara Municipal. Ao perceberem como ela era antes, no momento em que entraram para o serviço público, e agora, sentem que participaram das mudanças, das melhorias e que, efetivamente, fizeram algo que contribuiu e engrandeceu o ambiente de trabalho. Eles também sentem prazer por exercerem suas tarefas com denodo e ter a consciência tranquila por estarem doando o melhor de si a cada dia.

Há liberdade para expressarem suas opiniões sobre o trabalho, elas são bem aceitas pela chefia, sobretudo porque há tarefas que são de vital importância, cuja execução pode intervir no bom andamento e funcionamento da Câmara, como é o caso das finanças, que é regida por lei federal e auditada pelo Tribunal de Contas do Estado.

Os funcionários públicos sentem prazer também quando seus esforços são reconhecidos pelos colegas e pelos superiores e pela sensação de dever cumprido e de reconhecimento de que o melhor está sendo feito, a todo o momento, e que as obrigações dos setores estão sendo cumpridas com denodo e no tempo preciso. 
Em relação ao sofrimento no trabalho, percebeu-se que, embora haja, em alguns casos, reconhecimento de que as tarefas foram bem desempenhadas, o reconhecimento por meio de gratificações, melhorias nos salários ou ocupação de cargos melhores ocorre por interesse político, por conchavos ou amizades, distendendo disso graves descontentamentos e desmotivação para os funcionários públicos que, ao longo da carreira, ficam relegados à margem desses benefícios. Decorre daí, também, o sentimento de injustiça e discriminação, pois não há critérios profissionais ou embasamento racional para auferir essas benesses, deixando o trabalhador desalentado, vendo que, independentemente de seus esforços, ocupa uma posição estática e imutável.

Como respeito aos danos físicos, observou-se que, ao longo do tempo, houve problemas como: diminuição na audição, L.E.R, bursite, problemas no joelho e, em alguns casos, devido ao sedentarismo, ganho de peso, que interferem na boa execução das tarefas e na saúde dos trabalhadores.

Quanto às estratégias para lidar com o sofrimento no trabalho, notou-se que são utilizadas estratégias individuais, que visam ao equilíbrio psíquico e à boa convivência social, à fé, à paciência, à ideia de que ali se consegue o sustento e auxílio para a família, à ideia de que todas as dificuldades enfrentadas ali irão passar, de que há coisas importantes fora do trabalho e que se deve dar mais valor à família, ao lazer e ao entretenimento.

\section{REFERÊNCIAS}

ALENCAR, E. M. L. S.. A repressão ao potencial criador. Psicologia: Ciência e Profissão, Brasília, v.9, n.3, p.11-13, 1989.

AMORIM, M. V.; CAMPOS, A. C. C. F.. A felicidade no trabalho: estudo sobre sua revelação e articulação com a produtividade: estudo piloto. In: ENCONTRO NACIONAL DE ENGENHARIA DE PRODUÇÃO, 22, Curitiba. Anais. Rio de Janeiro: ABEPRO, 2002.

ALVES-MAZZOTTI, A. J.; GEWANDSZNAJDER, F.. O método nas ciências naturais e sociais: pesquisa quantitativa e qualitativa. São Paulo: Thompson, 1999.

BARROS, N. M. G. C.. Riscos de adoecimento no trabalho: estudo com médicos e enfermeiros emergencialistas em um hospital regional mato-grossense. Dissertação (Mestrado em Administração) - Faculdade Novos Horizontes, Belo Horizonte. 2012

BARROS, A. J. S.; LEHFELD, N. A. S.. Fundamentos de metodologia científica: um guia para a iniciação científica. 2 ed. São Paulo: Pearson Education do Brasil, 2000.

BRANT, L. C.; MINAYO-GOMEZ, C.. A transformação do sofrimento em adoecimento: do nascimento da clínica à psicodinâmica do trabalho. Ciência e Saúde Coletiva, Rio de Janeiro, v.9, n.1, p.213-223, 2004.

CARNEIRO, S. A. M.. Trabalho e violência: relação de proximidade da violência a trabalhadores durante jornada de trabalho, na Zona Norte de São Paulo, em 1998. Dissertação (Mestrado em Saúde Pública) - Universidade de São Paulo, São Paulo, 2000.
CARRASQUEIRA, F. A.; BARBARINI, N.. Psicodinâmica do Trabalho: uma reflexão acerca do sofrimento mental nas organizações. Jornada de Saúde Mental e Psicanálise da PUCPR, Curitiba, v.5, n.1, p.1-19, 2010.

CERVO, A. L.; BERVIAN, P. A.; DA SILVA, R.. Metodologia científica. 6. ed. São Paulo: Prentice Hall, 2007.

CHANLAT, F.. Modos de gestão, saúde e segurança no trabalho. In: DAVEL, E. P. B.; VASCONCELOS, J. G. M. Recursos humanos e subjetividade. Petrópolis: Vozes, 1996. p.208-229.

DEJOURS, C.. O trabalho como enigma. In: LANCMAN, S. SZNELWAR, L. I.. Christophe Dejours: da psicopatologia à psicodinâmica do trabalho. Rio de Janeiro: Fiocruz, 2004. p.127-139.

DEJOURS, C.. A loucura do trabalho: estudo de psicopatologia do trabalho. São Paulo: Cortez-Oboré, 1987.

DEJOURS, C.. A carga psíquica do trabalho. In: DEJOURS, C.; ABDOUCHELI, E.; JAYET, C.. Psicodinâmica do trabalho: contribuições da Escola Dejouriana à análise da relação prazer, sofrimento e trabalho. São Paulo: Atlas, 1994. p.2131.

DEJOURS, C.. A loucura do trabalho: estudo de psicopatologia do trabalho. 5 ed. São Paulo: Cortez-Oboré, 1992.

DI PIETRO, M. S. Z.. Direito Administrativo. 17 ed. São Paulo: Atlas, 2004. 
GIL, A. C.. Métodos e técnicas de pesquisa social. São Paulo: Atlas, 1999..

GODOY, A. S.. Introdução à pesquisa qualitativa e suas possibilidades. Revista de Administração de Empresas, São Paulo, v.35, n.2, p.57-63, 1995.

HELLER, A.. O cotidiano e a história. São Paulo: Paz e Terra, 2000.

LUDKE, M.; ANDRÉ, M. E. D. A.. Pesquisa em educação: abordagens qualitativas. São Paulo: EPU, 1986.

MACÊDO, K. B.; FLEURY, A. R. D.. O mal-estar docente para além da modernidade: uma análise psicodinâmica. Revista Amazônica, Manaus, v.5, v.9, n.2, p.217-238, 2012

MENDES, A. M. B.; FERREIRA, M. C.. Inventário sobre trabalho e riscos de adoecimento - ITRA: instrumento auxiliar de diagnóstico de indicadores críticos no trabalho. In: MENDES, A. M.. Psicodinâmica do trabalho: teoria, método e pesquisas. São Paulo: Casa do Psicólogo, 2007. p.111-126.

MENDES, A. M. B.; ABRAHÃO, J. I.. A influência da organização do trabalho nas vivências de prazer-sofrimento dos trabalhadores: uma abordagem psicodinâmica. Revista Psicologia Teoria e Pesquisa, Brasília, v.26, n.2, p.179-184, 1996.

MENDES, A. M. B.; MORRONE, C. F.. Vivências do prazersofrimento e saúde psíquica no trabalho: trajetória conceitual e empírica. In: MENDES, A. M. B.; BORGES, L. O; FERREIRA, M. C.. Trabalho em transição: saúde em Risco. Brasília: EDUNB, 2002. p.25-42.

MENDES, A. M. B.. Valores e vivência de prazer e sofrimento no trabalho. Tese (Doutorado em Psicologia) Universidade de Brasília, Brasília, 1999.
MENDES, A. M. B.. Os novos paradigmas de organização do trabalho: implicações para saúde mental do trabalhador. Revista de Psicologia, São Paulo, v.13, n.1, p.27-32, 1996.

MINAYO, M. C. D. S.. O desafio do conhecimento: pesquisa em saúde. 4 ed. São Paulo, 1996.

OLIVEIRA, R. C. M.. A configuração da QVT no contexto de trabalho dos detetives da polícia civil metropolitana de Belo Horizonte. Dissertação (Mestrado em Ciências Econômicas) - Universidade Federal de Minas Gerais, Belo Horizonte, 2001.

OLIVEIRA, D. S.; VIEIRA, F. O.. Sofrimento no trabalho: uma carona com os motoristas de ônibus em GPR. In: ENCONTRO DE GESTÃO DE PESSOAS E RELAÇÕES DE TRABALHO, 2. Anais. Curitiba: EGPRT, 2009.

SCHUTZ, W. C.. O prazer: expansão da consciência humana. Rio de Janeiro: Imago, 1974.

SOTO, E.. Comportamento organizacional: o impacto das emoções. São Paulo: Pioneira Thomson Learning, 2002.

TAMAYO, A.. Cultura e saúde nas organizações. Porto Alegre: Artmed,

2004.

TRIVIÑOS, A. N. S.. A pesquisa qualitativa em educação. São Paulo: Atlas, 1987.

VERGARA, S. C.. Projetos e relatórios de pesquisa em administração. 9 ed. São Paulo: Atlas, 2007.

YIN, R. K.. Estudo de caso: planejamento e métodos. 2 ed. Porto Alegre: Bookman, 2010. 